\title{
A COEDUCACIÓN DAS EMOCIÓNS COMO ESTRATEXIA CHAVE PARA A PROMOCIÓN DA CONVIVENCIA POSITIVA: A EXPERIENCIA "EMOCIONADXS" DO IES "XULIÁN MAGARIÑOS" (NEGREIRA)
}

\author{
THE EDUCATION OF EMOTIONS AS A KEY STRATEGY \\ FOR THE PROMOTION OF POSITIVE COEXISTENCE: THE EXPERIENCE \\ “EMOCIONADXS", DEVELOPED AT "XULIÁN MAGARIÑOS" INSTITUTE (NEGREIRA)
}

\author{
Aixa Permuy Martínez \\ Instituto de Ciencias da Educación da Universidade de Santiago de Compostela \\ aixa.pm@gmail.com
}

Begoña Cortés Ferro Instituto de Ensinanza Secundaria "Xulián Magariños” begonacortes69@gmail.com

\section{RESUMO}

"EmocionadXs" (Permuy, 2013), nomea un proxecto de educación-coeducación das emocións para alumnado de Educación Secundaria Obrigatoria (ESO), desenvolto durante tres cursos académicos no Instituto "Xulián Magariños" de Negreira, unha pequena localidade semi rural da provincia de A Coruña.

Neste artigo expóñense algúns dos resultados de dito proxecto, co fin de evidenciar os efectos da educación das emocións nas relacións de convivencia no centro. Así, apoiándose nas testemuñas de persoal docente chave, o estudo manifesta a necesidade e pertinencia de deseñar e implementar accións de carácter socioeducativo, enfocadas á promoción dun desenvolvemento emocional saudable no alumnado.

A investigación confirma que a educación das emocións contribúe a crear oportunidades de aprendizaxe compartida entre a rapazada, a través de experiencias e vivencias motivadoras, emocionantes e significativas; implicando ás persoas, dun xeito explícito, no seu propio proceso de desenvolvemento, tanto persoal como grupal.

Neste senso, para a creación de contextos de convivencia positiva, parece imprescindible ter presentes a dimensión emocional e social do individuo, pero tamén dos grupos.

Como afirmaba Paulo Freire "a Educación non cambia o mundo, cambia ás persoas que van cambiar o mundo". Por iso, a transformación social, cara unha cultura de paz, depende en gran medida de aprenderse como suxeito emocional e social, en interacción coas outras persoas e as súas emocionalidades; e 
por tanto, aprenderse como individuo pensante e sentinte, responsable da propia vida e da vida en comunidade.

"EmocionadXs" (Permuy, 2013) é unha experiencia deseñada e implementada desde o Seminario de Emocionalidade, Xéneros e Desenvolvemento Humano (EXDEHU), do Instituto de Ciencias da Educación da Universidade de Santiago de Compostela.

Palabras chave: educación das emocións, emocións, coeducación, convivencia positiva.

\section{ABSTRACT}

"EmocionadXs" names an education-emotion coeducation project for compulsory secondary education students (ESO, in its acronym in Galician), developed during three academic years in the Institute "Xulián Magariños" of Negreira, a small semi-rural town in the province of A Coruña.

This article presents some of the results of this project, in order to highlight the effects of the education of the emotions in the relations of coexistence in the center. Thus, based on the testimonies of key teaching staff, the study shows the need and relevance of designing and implementing socioeducational actions focused on the promotion of healthy emotional development in students.

Research confirms that the education of emotions contributes to create diverse opportunities for shared learning among teenagers, through motivating, exciting and meaningful experiences; implying people, in an explicit way, in their own development process, both personal and group.

In this sense, for the creation of contexts of positive coexistence, it seems essential to keep in mind the emotional and social dimension of the individual, but also of the groups.

As Paulo Freire affirmed "Education doesn't change the world, it changes people who are going to change the world". For this reason, social transformation, towards a culture of peace, depends to a great extent on learning as an emotional and social subject, in interaction with other people and their emotionalities; and therefore, to learn as a thinking and feeling individual, responsible for his own life and the life in community.

"EmocionadXs" (Permuy, 2013) is an experience designed and implemented since the Permanent Seminar of Emotionality, Gender and Human Development (EXDEHU, in its acronym in Galician), of the Institute of Sciences of the Education of the University of Santiago de Compostela.

Key words: education of emotions, emotions, co-education, positive coexistence.

\section{INTRODUCIÓN}

Este artigo recolle parte dos resultados dunha investigación máis ampla, enmarcada nun proxecto de tese de doutoramento, sobre a educación-coeducación das emocións como estratexia para a promoción do desenvolvemento integral non sexista do alumnado de Educación Secundaria Obrigatoria (ESO), nun centro educativo da Comunidade Autónoma Galega, o IES "Xulián Magariños" de Negreira.

Trátase dun estudo de caso que, desde a súa validez ecolóxica, pretende poñer de manifesto as bondades de levar ás aulas de Secundaria, accións enfocadas ao desenvolvemento e adestramento das competencias emocionais, tanto para as persoas, individualmente, como para os grupos e, por tanto, para a convivencia.

Neste senso, "EmocionadXs" (Permuy, 2013) aspira a fomentar o desenvolvemento desas competencias emocionais e sociais no alumnado da ESO, potenciando o empoderamento da rapazada 
participante. Para a construción de identidades auténticas, equilibradas e responsables, favorece cuestionarse o propio ser, desbotando os estereotipos e os encargos asociados aos distintos xéneros, e que se derivan do sistema sociocultural patriarcal.

Así, a particularidade de "EmocionadXs" (Permuy, 2013), dentro das accións existentes dirixidas ao desenvolvemento emocional, é o seu enfoque coeducativo no traballo coas emocións. Un enfoque que revirte non só na forma de abordar os contidos, senón tamén á hora de definir os obxectivos da intervención, deseñar as ferramentas, aplicar as actividades, analizar os resultados, etc.

Delimitar e xustificar o concepto de educación das emocións será esencial para entender así as finalidades do proxecto e os seus resultados, pero ademais, a relación entre a propia educación das emocións e a convivencia positiva.

Porén, antes de abordar esta conceptualización, é pertinente sinalar que "EmocionadXs" (Permuy, 2013) fundaméntase, entre outras, na necesidade contemporánea de aprender a convivir en benestar, xa que, como indican Valdemoros e Goicoechea (2012, p. 11), "a educación para a convivencia constitúe unha aprendizaxe necesaria na sociedade actual do século XXI.”

Deste xeito, sabendo que as competencias emocionais serven para favorecer e mellorar as nosas relacións intra e interpersoais, pódese afirmar que o traballo para o seu desenvolvemento resulta imprescindible, xa non so para a convivencia escolar, senón para a vida en sociedade. E xa que estas competencias teñen unha incidencia directa sobre os procesos de convivencia entre as persoas, estaríase afirmando así que a educación das emocións pode entenderse como unha educación para a vida.

\section{CONTEXTUALIZACIÓN: EDUCACIÓN DAS EMOCIÓNS E CONVIVENCIA POSITIVA NO IES “XULIÁN MAGARIÑOS” DE NEGREIRA}

Negreira forma parte dunha bisbarra eminentemente rural. A agricultura, a gandería e o comercio son as súas principais fontes de riqueza. As remesas da emigración, a man de obra na construción, pequenos obradoiros e unha factoría de agroindustria -a Cooperativa Feiraco-, completan os fíos do seu tecido económico.

Neste contexto sitúase o Instituto de Ensinanza Secundaria “Xulián Magariños”, no Concello de Negreira, na provincia de A Coruña. Como centro educativo nace no ano 1981, en forma de Colexio Municipal Homologado de Bacharelato, pasando despois a ser IESP e finalmente IES.

Actualmente impártense ensinanzas dos catro cursos de Educación Secundaria Obrigatoria (ESO), Bacharelato e os ciclos formativos de Grao Medio de Comercio, Grao Superior de Administración de Sistemas Informáticos en Rede, e ademais, a Formación Profesional Básica, na especialidade de Comercio, para un total de máis ou menos 400 alumnos e alumnas, e contando para isto con 50 docentes.

No relativo ao traballo pola convivencia, o "Xulián Magariños" é un centro exemplar no territorio autonómico; precursor na inclusión de poboación estranxeira, concretamente a e orixe 
norte-africano, ten acadado importantes éxitos na posta en marcha de diferentes accións e actividades de promoción da convivencia positiva e saudable na súas aulas.

Neste senso, conta cunha longa e significativa experiencia en mediación entre iguais, unha estratexia chave para o fomento desta convivencia positiva, tendo no seu centro un dos servizos de mediación escolar máis consolidados do panorama actual, non so polo seu percorrido histórico, senón tamén pola súa eficacia. Tamén forma parte doutras experiencias educativas innovadoras, a favor do benestar e a convivencia, como a Titoría entre Iguais (TEI), sendo parte imprescindible do Grupo de Traballo "TEI Galicia” do Instituto de Ciencias da Educación da Universidade de Santiago de Compostela. Ademais conta cun dos primeiros proxectos de educación emocional e social para a Educación Secundaria Obrigatoria da nosa Comunidade, recoñecido na IV convocatoria de Proxectos Escolares Educabarrié, da Fundación Barrié de la Maza.

No seu percorrido ten acumulados moi variados e importantes premios, especialmente no tocante á produción audiovisual de materiais educativos, creados e realizados polo seu alumnado, e relacionados tamén con temas vencellados á convivencia positiva. Este é o caso do segundo premio do Parlamento de Galicia 2015 pola curta “Amar é sinónimo de respectar”, pola que tamén acadou un accésit no Festival de Cine Escolar Olloboi, no curso 2014/2015, e no Festival de Cine Internacional de Ourense 2015.

Deste xeito, como se pode ver, o "Xulián Magariños" conta con diversas iniciativas, de variadas temáticas, pero sempre na liña da mellora da convivencia e da innovación educativa; tamén son exemplo destas accións o seu Proxecto de Aprendizaxe e Servizo e a organización, xunto con outros centros educativos galegos, dos Encontros Anuais para unha Convivencia Positiva, que xa van pola súa quinta edición.

Estas actividades son os produtos dunha comunidade educativa tremendamente activa e dinámica que, eficazmente guiada, tanto pola dirección do Centro como polo Departamento de Orientación, procura estar sempre á vangarda educativa.

Así, coa clara intención de traballar arreo pola promoción da convivencia positiva, desde unha perspectiva de innovación e transformación social, iniciou a súa colaboración co Seminario Permanente EXDEHU, para levar ás súas aulas a experiencia de educación das emocións "EmocionadXs" (Permuy, 2013).

\section{MARCO TEÓRICO DA EDUCACIÓN DAS EMOCIÓNS}

A educación das emocións emerxe como resposta ante as esixencias da sociedade contemporánea, pero ademais, ante a necesidade eminentemente humana de perseguir o benestar subxectivo. Enténdese como un proceso permanente, -presente ao longo de toda a vida-, e continuo, -en constante construción-, que pretende potenciar o desenvolvemento integral das persoas, poñendo o foco da súa acción nos ámbitos emocionais e sociais da identidade. 


\subsection{Delimitación conceptual da educación das emocións}

A educación das emocións, dentro das ciencias da afectividade, pode definirse como un corpo teórico-práctico nacido da combinación entre a educación emocional, a perspectiva de xéneros e a coeducación (Berastegui e Permuy, 2017). Refírese a un proceso, continuado e permanente, que serve para acadar un desenvolvemento humano integral, equilibrado e libre; ou o que é o mesmo, un desenvolvemento humano equilibre (termo que se agradece a Rosa Sanchís, xurdido no contexto dunha conversa sobre as emocións no ano 2016).

A educación das emocións cobra todo o seu sentido no marco sociocultural contemporáneo porque se presenta como unha práctica coeducativa andróxina que permite ás persoas desenvolverse, nos seus ámbitos emocional e social, liberadas dos encargos (cognitivos, emocionais e comportamentais) herdados do sistema patriarcal e impostos a través dos estereotipos e roles de xéneros; encargos que, claramente, condicionan tanto a vida como as relacións e a convivencia.

Porén, á marxe destes condicionantes socioculturais, todas e todos somos seres emocionais; de feito, en palabras de Mora (2014, p. 14):

A emoción é ese motor que todos levamos dentro. Unha enerxía codificada en certos circuítos neuronais localizados en zonas profundas do noso cerebro (no sistema límbico) que nos move e nos empurra «a vivir», a querer estar vivos e en interacción constante co mundo e con nos mesmos.

Deste xeito, as emocións, afectan aos pensamentos, pero tamén ás condutas, mediatizadas pola carga cultural á que están asociadas. E adoitan provocar unha forma concreta de comportamento, tal e como afirma Bisquerra (2009): móvennos á fuxida, ou ben á confronta. Así, ante unha emoción so se poderán dar dous tipos de resposta: o bloqueo (ou negación), ou ben o afrontamento (ou aceptación).

Teña a natureza que teña a emoción (positiva, negativa, ambigua ou estética), sempre terá algunha función, e por iso debería poder experimentarse con total liberdade, sexa un socializado varón, ou unha socializada muller; buscando o xeito de aproveitar o seu impulso, esa enerxía motora que proporciona, ao noso favor. De feito, segundo Bisquerra (2009), algunhas das funcións que teñen as emocións para a vida están relacionadas con esa forza motivadora das condutas, con que funcionan como elementos de adaptación á contorna, informan, alterando o equilibrio orgánico (por exemplo, ante un perigo), e serven ademais para comunicar ao mundo exterior o que nos está a pasar por dentro, e incluso para influír nas demais persoas.

Neste senso, as emocións, desde a súa diversidade práctica, adoitan xogar un importante papel no desenvolvemento persoal e no benestar, individual e colectivo.

As emocións aféctannos globalmente, actuando de formas distintas en cada persoa (provocando comportamentos e pensamentos máis ou menos adaptativos, segundo o caso); e por iso é tan importante o desenvolvemento das competencias emocionais, porque fan posible a xestión eficaz destas emocións. "As emocións son como os piares básicos sobre os que repousan case todas as funcións do cerebro” (Mora, 2012, p.18), de aí o imprescindible de aprender a empregalas a favor 
do benestar, coa conciencia de que sempre se experimentan baixo as influenzas da sociocultura, tanto no tocante á atribución de sentido, como no que respecta á autopercepción sobre as posibilidades de expresión.

A educación das emocións materialízase por tanto nun proceso de reflexión dialóxica, toma de conciencia, asunción da responsabilidade, aprendizaxe e ensino; que se sucede seguindo estas fases, sucesivamente, nun tránsito constante adiante-atrás.

Ditas fases vanse sucedendo a medida que se adquiren e desenvolven as competencias emocionais; concretamente, as que se recollen no modelo pentagonal de competencias emocionais de Bisquerra e Pérez Escoda (Pérez Escoda, 2016): a conciencia emocional, a regulación, a autonomía emocional, a competencia social e as competencias para a vida e o benestar.

Para lograr a adquisición e o adestramento destas competencias, a educación das emocións, como se comentaba anteriormente, estrutúrase a partir dunha serie de fases: reflexión dialóxica, toma de conciencia, asunción da responsabilidade, aprendizaxe e ensino.

O inicio do proceso comeza na reflexión dialóxica entre a persoa (alumno/alumna), o grupo, os contidos e a persoa formadora. Nesta fase prodúcese a toma de contacto coa temática, a partir dunha mirada introspectiva sobre o significado de sentir e sentirse na propia vida. Esta reflexión será a que dea paso ao seguinte momento do proceso, a toma de conciencia. A persoa recoñécese, no aquí e no agora, como suxeito de emoción, construída a partir de valores, crenzas e estereotipos, nesgada polo marco sociocultural no que se atopa inserida. Neste punto xoga un papel fundamental a perspectiva de xéneros, facendo posible unha conciencia moito máis auténtica e realista sobre a emocionalidade e a identidade. Seguindo a Permuy e Méndez (2016), o sistema patriarcal inflúe nos modelos de pensamento e comportamento de todas as persoas, "establecendo" diferentes arquetipos (intelectuais, profesionais, afectivos, emocionais e comportamentais), socialmente aceptables, aínda que non todos ni para todo o mundo. Porén, no imaxinario social existen pensamentos, pero tamén condutas e "formas de ser", eminentemente masculinas ou femininas que limitan a nosa forma de performar tanto a identidade como a emocionalidade.

Esta fase do proceso da educación das emocións permite desenvolver unha conciencia emocional que cuestiona explicitamente estes estándares do patriarcado, facilitando a entrada á seguinte fase, -de asunción da responsabilidade-, dun xeito máis contundente.

Esa responsabilidade ven dada a partir da comprensión que provocan o autocoñecemento e a reflexión sobre un/unha en relación co mundo. O que se pretende é motivar un posicionamento o máis libre posible fronte a propia vida, a adopción dunha actitude de presenza e poder conscientes. Aquí serán a autonomía e a regulación emocional as competencias que se desenvolvan, pois permiten chegar a ese estado de responsabilidade e vontade sobre o que se sinte, e sobre como ese sentir se traduce en acción.

Este estado será o que permita adquirir as aprendizaxes relativas ao que un/unha é, ao que sinte e ao que desexa, para si e para as outras persoas; pero ademais, fará posible chegar a un punto no que se teñan adquirido esas competencias (conciencia, regulación e autonomía emocional) que contribúan a unha mellor relación cun/cunha mesmo/a, pero tamén co mundo. 
Estas aprendizaxes darán paso á entrada na fase de ensino, que chega cando se poñen en interacción as propias aprendizaxes coas das demais persoas. Un ensino que so será posible a partir de comportamentos coherentes, positivos e saudables, nos que se apliquen unhas habilidades sociais axeitadas para a construción do benestar persoal e comunitario. Nesta fase, por tanto, desenvólvense tanto a competencia social como as competencias para a vida e o benestar.

É importante indicar que o procedemento da educación das emocións non é lineal, nin unidireccional, senón que se integra na persoa e no grupo, adaptándose á súa vivencia durante todos os momentos nos que se aplica.

Como se pode deducir, a educación das emocións está relacionada de forma interdependente coas estruturas morais do pensamento e do comportamento, cos valores e coas crenzas individuais e culturais. Consiste nunha experiencia educativa que estimula a autoobservación fronte a todo ese sistema construído en interacción coa sociocultura e que, como se ten indicado, é claramente patriarcal.

Así, a educación das emocións é unha práctica que se aplica sobre todas as dimensións do "ser": sobre o pensar, sobre o facer e sobre o sentir; dimensións que se transforman en funcións humanas integradas e holísticas. "Cando sentimos, pensamos e actuamos; cando actuamos, sentimos e pensamos; e cando pensamos, sentimos e actuamos. Por que? Porque os humanos raramente so sentimos, so pensamos ou so actuamos" (Ellis e MacLaren, 2004, p. 11).

Neste sentido, a educación das emocións diríxese ao desenvolvemento das competencias emocionais e sociais, tendo presente a perspectiva de xéneros e facendo posible que as persoas se constrúan desde identidades (cognitivas, comportamentais e emocionais) alternativas e ambiguas, respecto da norma, se así o desexan. Significa desenvolverse ao marxe da caracterización cultural que afecta ao ser (en canto a súa esencia feminina ou masculina).

A vida, tal e como se comprende nesta época contemporánea, evidencia o imprescindible de educar as emocións desde esta perspectiva de fomento da igualdade de oportunidades (emocionais e sociais) para todas as persoas. E máis especificamente, a necesidade deste tipo de educación que empodera aos individuos, facendo posible o desenvolvemento do seu máximo potencial (persoal, académico, familiar...) alá onde a súa vontade lles leve, lonxe das expectativas socioculturais patriarcais que se viven como obrigas implícitas.

\subsection{Xustificación da educación das emocións na etapa da ESO para a promoción da convivencia positiva}

A educación das emocións xorde como complemento imprescindible ás ensinanzas desenvoltas nos sistemas de educación formal. A súa aparición xustifícase a partir das necesidades sociais que non se atopan atendidas dun xeito máis explícito desde a escola.

Neste senso, tomando como referencia os principais problemas que preocupan á sociedade española, segundo os datos do Centro de Investigacións Sociolóxicas (CIS) (2016), por orde de prioridade, poden atoparse: o desemprego, a corrupción, o fraude e, en xeral, os problemas de índole económica. 
Pero ademais, entre estas problemáticas máis destacadas, tamén aparecen como focos de preocupación: a sanidade, os problemas sociais, a educación, a inseguridade cidadá, a violencia contra as mulleres, o consumo e venta de drogas...

Sen dúbida, algúns destes fenómenos teñen un claro compoñente emocional, estando vencellados, en moitos dos casos, a procesos de vulnerabilidade, dificultades para a regulación emocional, carencia de autonomía ou baixa autoestima, como ocorre por exemplo nos casos de consumo de drogas ou nos comportamentos violentos.

Desde os contextos educativos formais non se consegue atender a estes asuntos e por iso, a educación das emocións, entendida como unha educación para a vida, emerxe co obxectivo de atender estas necesidades relacionadas cun desenvolvemento persoal integral, saudable e equilibrado.

Na actualidade, como reflexiona Lladó Moreno (2012), vivimos tempos nos que se están a producir fortes diferenzas culturais, distintos tipos de familias e modelos de comportamento social moi variados. A influenza da publicidade e dos medios de comunicación de masas é esaxerada; igual que a tendencia a un individualismo radical que, acompañado de habituais cambios de residencia, favorecen o illamento das persoas, deixándoas á marxe de posibles redes sociais de apoio, ou tecidos afectivos significativos.

E por riba, son tempos hiperinformados. Os discursos sobre a infancia e a xuventude, e todo o que lles afecta, proliferan, así como a literatura sobre as estratexias para o afrontamento das dificultades que comportan estas etapas evolutivas; o que non implica que exista unha información máis rigorosa ou de utilidade. Poderíase dicir que hai moitos e diferentes discursos, pero pouco coñecemento.

Nesta situación de globalización e capitalismo, parece inevitable que suframos a desigualdade, cada vez máis intensamente; o paradigma dunha equidade na educación está lonxe de ser unha realidade. Así, a educación das emocións, entendida como ese corpo teórico-práctico, enfocado cara á liberación e o desenvolvemento do máximo potencial emocional e social das persoas, emerxe como unha alternativa metodolóxica e de contidos tremendamente interesante para dar resposta, de forma eficaz, a estas esixencias da vida contemporánea.

A educación das emocións nace, por tanto, como unha medida educativa innovadora enfocada, seguindo a Berastegui (2016), a:

- Promover a saúde emocional e mellorar as relacións sociais.

- Resolver conflitos e contradicións intrapersoais, potenciando o autocoñecemento e o recoñecemento.

- Promovero desenvolvemento de competencias emocionais, atendendo ao desenvolvemento da personalidade integral das persoas (sobre todo na infancia e na xuventude).

- Mellorar o clima convivencial da aula e do centro, diminuíndo a conflitividade.

- Orientar á infancia e á xuventude no tránsito á vida profesional e adulta, reducindo as situacións de fracaso escolar e ou risco de exclusión. 
- Afianzar o apoio emocional no profesorado, promovendo emocións positivas nos procesos de aprendizaxe.

Por tanto, a educación das emocións actúa como unha ferramenta de prevención primaria, aplicándose a toda a infancia e xuventude, sen ter en conta os diferentes niveis de risco. Consiste nunha intervención dirixida á promoción da saúde e o benestar; unha forma de prevención que pretende minimizar, dentro do posible, a aparición de factores ameazantes (entendidos como circunstancias ou situacións que aumentan as probabilidades de que se produza unha dificultade ou problemática na vida dunha persoa). Pero ademais, ao falar de educación das emocións como prevención primaria, faise referencia a unha acción que ten por obxectivo preparar aos individuos e aos grupos para reaccionar de forma eficaz e saudable ante situacións de perigo para o seu equilibrio e benestar.

Este enfoque para a fundamentación da educación das emocións, entendida como resposta ante as necesidades sociais desatendidas desde a escola, é o habitual. Porén, deixando a unha marxe todos eses factores ameazantes, para o individuo e para o grupo, que se deben previr empregando a educación das emocións, parece interesante abrir a perspectiva, especialmente cando se pensa nesta intervención na Educación Secundaria Obrigatoria.

Así, recorrendo á filosofía atópanse interesantes reflexións, relacionadas co sentido da vida, a construción da identidade responsable e libre, e a busca da felicidade, que parece pertinente incorporar, aínda que sexa dun xeito superficial, como outro dos elementos fundamentais que xustifican a incorporación da educación das emocións ás aulas de Secundaria.

A filosofía destaca á persoa, ao ser humano, como creadora do significado da súa propia vida. Como recolle Astrada (1949, p. 350) "a filosofía debe ter por obxecto a existencia do home, tomado integralmente". Dentro desta ciencia, a corrente existencialista, desenvolta entre os séculos XIX e $\mathrm{XX}$, defende que cada persoa compón unha integridade libre por si mesma; o pensamento fai que a persoa sexa libre e sen liberdade non hai existencia. Así, preséntase unha clara busca do sentido da vida e da existencia a partir da individualidade feita emoción, acción, decisión e responsabilidade.

A conciencia sobre unha existencia concreta no mundo, nun momento e nun espazo específicos e determinados, é un dos elementos constitutivos do ser. E aínda sabendo que esta existencia é arbitraria, un capricho, como diría Sartre (2009), estamos na obriga de padecer e xestionar emocións, positivas e negativas, ao igual que sentimentos, positivos e negativos. Isto é parte esencial da condición humana, vivir condenados/as a existir, decidindo como, aínda sen saber que facer, que pensar ou cara a onde ir en moitas ocasións. De aí que a vida teña sentido na medida en que cada persoa decida atribuírllo.

Cada individuo é quen debe atopar o para que da súa propia existencia, reflexionaba Kierkegaard (1813-1855) pai do existencialismo, pois a maior responsabilidade do ser humano radica en vivir a súa propia vida, con paixón e honestidade, porén das adversidades que poidan presentarse.

En consonancia con estes presupostos, e dentro das ideas defendidas polo feminismo filosófico de Emilie du Châtelet, xa no século XVIII, no seu Discurso sobre a felicidade, atópanse 
argumentos que permiten xustificar a educación das emocións, como unha ferramenta para moito máis que responder ás necesidades sociais da adolescencia.

A educación das emocións serve, ademais de para previr, para contribuír á toma de conciencia sobre o poder que ten cada persoa para definir o sentido da súa vida, e enfocalo, ou non, cara a construción do benestar subxectivo individual e comunitario. Nas propias palabras de Emilie du Châtelet (1996, pp. 95-96):

Anticipemos unhas reflexións que se fan cando xa é demasiado tarde; aqueles que as lean atoparán nelas o que a idade e as circunstancias da súa vida lles ofrecerían con demasiada lentitude. Impidamos que perdan unha parte do tempo precioso e escaso do que dispoñen para sentir e pensar, e que deban empregar en calafatear o barco momentos que lles servirían para procurarse os praceres que lles pode deparar a navegación.

Para ser felices, debemos desfacernos dos nosos prexuízos, ser virtuosos, gozar de boa saúde, ter inclinacións e paixóns, ser propensos á ilusión, e ai dos que a perdan! En lugar de tratar de facela desaparecer mercé ao facho da razón, tratemos de engrosar o verniz que deposita sobre a maior parte dos obxectos; é aínda máis necesario do que o son para os nosos corpos os coidados e o ornato.

"Preservémonos da ambición e, sobre todo, saibamos ben o que queremos ser; decidamos o camiño que queremos tomar para pasar a nosa vida e tratemos de sementalo de flores flores" (Châtelet (1996., p. 118).

Durante a Secundaria, en plena adolescencia, a xuventude atópase nun momento vital crucial para a construción da súa identidade persoal. A educación das emocións nesta etapa, ademais de pola necesidade de previr posibles desordes ou comportamentos de risco e problemas de convivencia, como se ten insistido, será fundamental polo funcional da súa acción para a cimentación da personalidade e a promoción de escollas libres e atentas na configuración do proxecto vital.

Neste senso, a educación das emocións trabállase como unha ferramenta ao servizo do coñecerse, recoñecerse e relacionarse; contribúe á toma de conciencia do que un/unha é, do que desexa ser e como quere vivir e convivir. Así, e dun xeito innegable, axuda a maximizar as oportunidades de adaptación social, facendo posible que cada persoa asuma a responsabilidade sobre a súa propia vida, consigo mesma pero tamén coa súa comunidade.

\section{DESEÑO DA INVESTIGACIÓN}

Esta investigación, no marco do proxecto de tese de doutoramento, contempla a complementariedade metodolóxica, combinando o enfoque cuantitativo e o cualitativo. Deste xeito, procúranse sumar as potencialidades destas dúas perspectivas, compensando as limitacións que presentan aplicadas por separado (Cea, 1997). Porén, no caso que nos ocupa, farase referencia a unha das partes cualitativas do estudo.

Co obxectivo de afondar nos discursos e narrativas, entre outros, sobre dos efectos da educación das emocións na convivencia escolar, realizouse un cuestionario de pregunta aberta, 
destinado ás dúas persoas do persoal docente máis involucradas no desenvolvemento do proxecto, durante os seus tres anos de duración.

A avaliación que se presenta é tan só unha parte da totalidade da avaliación do proxecto "EmocionadXs" (Permuy, 2013).

\subsection{Obxectivos}

- Presentar as opinións e reflexións do persoal docente máis involucrado no desenvolvemento do proxecto "EmocionadXs" (Permuy, 2013).

- Recoller datos sobre os efectos do proxecto, percibidos por este persoal docente.

- Poñer de manifesto a relación entre a educación das emocións e a convivencia positiva.

- Facer explícita a necesidade de incorporar accións de educación das emocións para o desenvolvemento integral non sexista do alumnado e a promoción da convivencia positiva nos centros educativos.

\subsection{Procedemento}

Deseñouse un cuestionario ad hoc, composto por cinco preguntas abertas, para recoller as percepcións do persoal docente.

Concretamente, propuxéronselles as seguintes cuestións:

1. Como describirías o proxecto "EmocionadXs", despois destes tres anos?

2. Que aporta este Proxecto ao alumnado participante, individual e colectivamente?

3. Cal é a túa percepción do que significou a experiencia "EmocionadXs" para os grupos participantes? E para o Centro?

4. Para ti, que significou participar neste Proxecto, persoal e profesionalmente?

5. Outros comentarios.

O instrumento aplicouse a unha titora e á orientadora, ao remate da intervención, durante a avaliación final. Aínda sendo un cuestionario anónimo, recolle datos respecto da idade, o cargo e a antigüidade no Centro das profesionais.

A análise do contido, baseado nas respostas destas docentes, así como a súa codificación, levouse a cabo mediante unha priorización da metodoloxía indutiva na construción de categorías (Boyatzis, 1998).

\section{RESULTADOS}

Para analizar os efectos da educación das emocións, entre outros aspectos, sobre a convivencia no centro, púxose o acento nesta parte cualitativa da avaliación final. 
Esta análise sobre as reflexións do persoal docente aportou argumentos que sustentan a necesidade de incorporar este tipo de actividades aos programas de promoción da convivencia positiva e de educación para a paz.

$\mathrm{Na}$ cuestión "que aporta este Proxecto ao alumnado participante, individual $e$ colectivamente?", as docentes fan referencia a un efectivo desenvolvemento de competencias emocionais como a conciencia, a regulación e a autonomía emocional, ademais de ás competencias sociais:

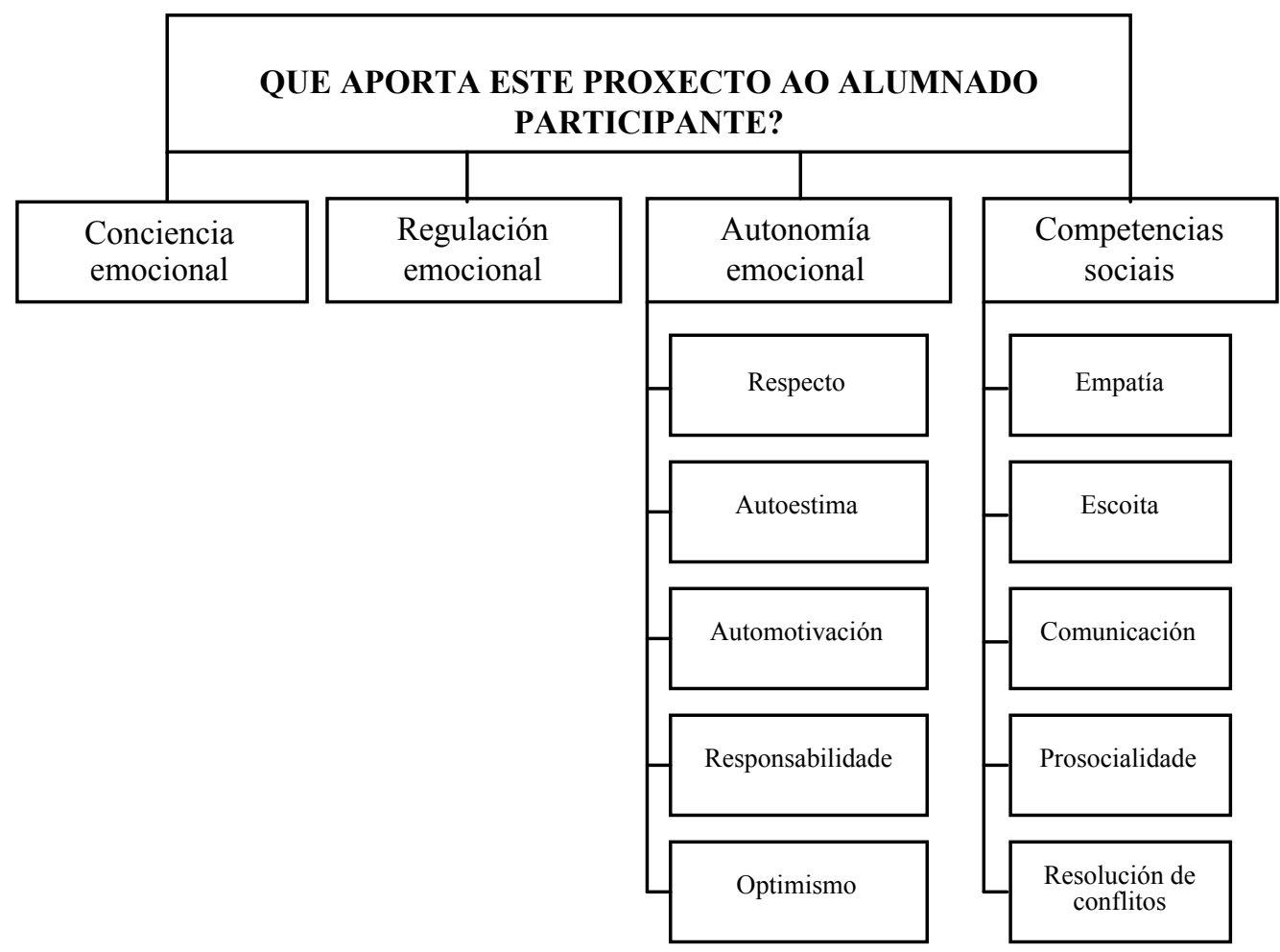

Figura 1. Aportacións do proxecto "EmocionadXs" ao alumando. Fonte: elaboración propia.

- Conciencia emocional: "Son capaces de poñerlles nome, empatizar cando son as doutras persoas".

- Regulación e autonomía emocional: "Xestionar ou colaborar de forma positiva na súa xestión".

- Autonomía emocional: "Proporciona ao alumnado a posibilidade de ser e estar dun xeito diferente, xestionando de xeito saudable as súas emocións e as alleas, nomeándoas e resolvendo os seus problemas dende o respecto a si mesmos/as e as demais persoas", "Dentro do centro educativo convertéronse nunha promoción admirada e respectada polo seu comportamento, o seu optimismo e o seu compromiso e o seu nivel de esixencia 
tamén é maior ca o doutras promocións, probablemente porque saben mellor identificar quen son, que senten e que desexan. Aínda así, con facilidade comprenden e respectan outros puntos de vista, iso si, sen deixarse manipular ou convencer con facilidade", "Son persoas moi activas nas actividades educativas e culturais".

- Competencias sociais: "Do punto de vista individual é máis complicado falar de cada unha delas e de cada un deles, as súas circunstancias son ben diferentes, como tamén o son os seus intereses. Porén, a individualidade, en xeral, deixa paso con certa facilidade ao grupo. Son, senten, funcionan e móvense como gran grupo definindo obxectivos comúns e negociando internamente a súa consecución. Iso convérteos en moi fortes dentro do centro educativo ou aló a onde vaian".

Na pregunta sobre "cal é a túa percepción do que significou a experiencia "EmocionadXs" para os grupos participantes? E para o Centro?”, as docentes insisten na consecución do desenvolvemento das competencias emocionais no alumnado, pero tamén a incorporación da educación das emocións á labor docente, como un aspecto imprescindible, e a mellora da convivencia no centro.

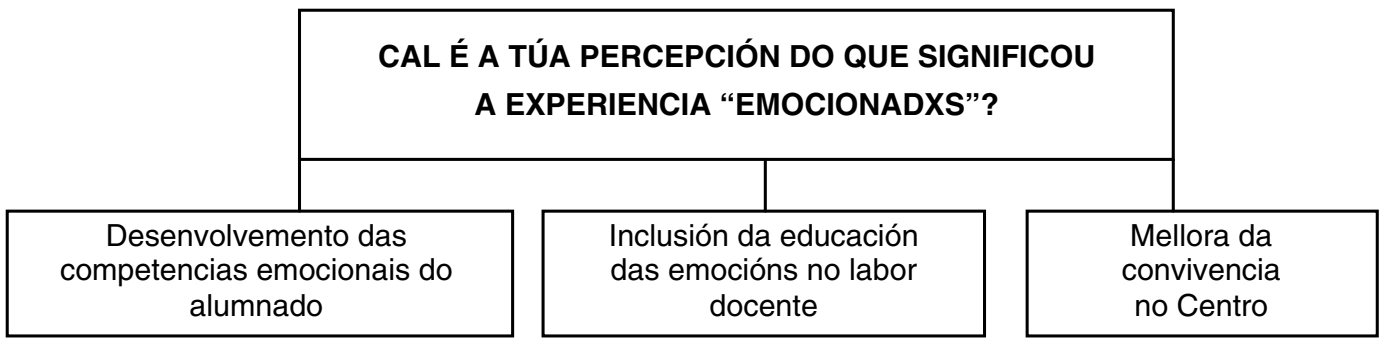

Figura 2. Percepción do significado da experiencia "EmocionadXs". Fonte: elaboración propia

- Desenvolvemento das competencias emocionais no alumnado: "Sen dúbida unha mellor relación consigo mesmos/as e os demais", "Estes grupos fluíron e flúen cunha enerxía diferente e contaxiosa que, entre outras moitísimas cousas, favorece o clima da aprendizaxe."

- Inclusión da educación das emocións na labor docente: "Supuxo un soporte perfecto para xestionar as emocións do alumnado, un ámbito para o que o claustro non estamos formados. Sen dúbida, foi a descuberta da educación emocional e do imprescindible que é no noso labor docente".

- Mellora da convivencia no centro: "Para o centro, unha mellora da convivencia".

\section{CONCLUSIÓNS}

Ao gallo dos resultados obtidos, a través desta parte da avaliación do proxecto, analizando as informacións recollidas sobre a perspectiva docente, pódese concluír que a educación das emocións 
contribúe ao desenvolvemento de competencias emocionais e sociais favorables á creación de contextos de convivencia positiva, como son a conciencia e a regulación emocional, a autonomía e as competencias sociais. Por tanto, considérase pertinente poñer en valor este tipo de actuacións como estratexias chave para a promoción tanto da convivencia positiva como da educación para a paz.

Cando unha persoa se sinte en benestar consigo mesma, porque sabe identificar e regular as súas emocións, se coñece, se acepta, vive con responsabilidade as súas decisións, trata con respecto e afecto ás demais persoas, comunícase e negocia con empatía e asertividade, etc., o contexto no que se atope inserida, sen dúbida, será moito máis pacífico, positivo e saudable que se a situación fose a contraria. Así, que as persoas cheguen a desenvolver e mellorar as súas competencias emocionais, sen dúbida, afectará ao clima dos grupos nos que se relacionen.

Neste sentido, nas repostas das docentes poden apreciarse reflexións que reflicten unha mellora do alumnado no tocante ás súas relacións tanto intra como interpersoais, grazas ao desenvolvemento das súas competencias emocionais; ademais, quedou manifesto que esta mellora no alumnado afectou, construtivamente, a outros grupos, e tamén á dinámica do centro.

Isto permite valorar moi positivamente a pertinencia e necesidade de continuar coa implementación de iniciativas deste tipo nos contextos escolares.

A educación-coeducación das emocións ten inmensas posibilidades para o desenvolvemento integral real da xuventude, presentando efectos e impactos moi significativos, para as persoas individualmente e para os grupos.

Así, a conclusión fundamental pasa por afirmar que ten todo o sentido do mundo incluír esta nova corrente metodolóxica (a coeducación) e de contidos (o emocional, o social e a convivencia) de maneira explícita nas aulas, aínda que a lexislación educativa siga priorizando os contidos científico-técnicos sobre o socioemocional.

Sobre todo, no momento que estamos a vivir, baixo unha sensación socialmente predominante de ruptura na convivencia, crise, inxustiza e desigualdade, parece que ten chegado a hora de deixar de ter que elixir, nos escenarios educativos da infancia e a adolescencia, entre o "saber" e o "sentir.

A coeducación das emocións, segundo Permuy e Méndez (2016), como se ten dito, debe ser unha ferramenta ao servizo do coñecerse, recoñecerse, relacionarse, actuar e decidir libremente no mundo. E como dentro dos encargos e os estereotipos do noso sistema sociocultural patriarcal resulta tremendamente complexo para case todas as persoas, por non dicir imposible, será imprescindible atopar a forma de potenciar esa construción sentida, libre e responsable da identidade, para a promoción dunha convivencia máis pacífica, a través de procesos de ensino-aprendizaxe que conecten con esta necesidade.

Desde este traballo, desde a experiencia "EmocionadXs" (Permuy, 2013), deféndese unha mirada e unha acción socioeducativa, -dentro da escola-, que cuestiona e deconstrúe estes contidos culturais asociados ao patriarcado. Deféndese unha educación-coeducación das emocións que permite, posibilita e valora o desenvolvemento integral non sexista de cada rapaz e cada rapaza, sexan 
cales sexan as súas características, a súa orixe, os seus desexos, as súas crenzas, os seus valores e os seus comportamentos, pero tamén da comunidade educativa. Unha educación para o ser libre e así, ser completo/a e convivir en benestar, tanto no intrapersoal como no interpersoal.

A educación-coeducación das emocións fai posible a prevención da violencia entre iguais desde unha perspectiva positiva e optimista, promovendo estratexias relacionais e convivenciais máis pacíficas e saudables; actuando ante os comportamentos desadaptativos, e fronte a unha ampla diversidade de situacións vitais do alumnado, activando todos os mecanismos posibles para axudar a que as persoas afronten a súa vida con poder e responsabilidade.

"EmocionadXs" (Permuy, 2013), aspira así a ser unha oportunidade de experiencia educativa que debe ser descuberta, interpretada, reconstruída, sentida e vivida desde as particularidades do seu contexto de aplicación e as das persoas que forman parte da mesma. Unha experiencia para coñecer e interiorizar a riqueza da emocionalidade, desde unha mirada coeducativa, pragmática, honesta, optimista e liberadora, que acompañe ao alumnado no seu autocoñecemento, buscando a súa implicación e promovendo o desenvolvemento de estratexias que contribúan ao impulso da súa aprendizaxe, do seu empoderamento e do seu benestar, tanto individual como colectivo.

Para rematar, aproveitar este espazo para agradecer á comunidade do IES “Xulián Magariños” de Negreira, en especial ao Departamento de Orientación e á Dirección do Centro, a súa confianza no Seminario de Emocionalidade, Xéneros e Desenvolvemento Humano (EXDEHU) do ICE da USC, para a posta en marcha deste traballo.

\section{REFERENCIAS}

Astrada, C. (1949). El existencialismo, filosofía de nuestra época. Actas del Primer Congreso Nacional de Filosofia, Argentina, tomo I. 349-358. Recuperado de http://www.filosofia.org/ aut/003/m49a0349.pdf

Berastegui, Y. (2016). Evaluación del desarrollo de la educación emocional en un centro educativo. (Tese doutoral). Euskal Herriko Unibersitatea/Universidad del País Vasco. Recuperado de https://addi.ehu.es/handle/10810/17917

Berastegui, Y. e Permuy, A. (2017). La relajación y la atención plena en el fútbol de alto rendimiento: educación de las emociones en las categorías base de la Real Sociedad de Fútbol S.A.D. (non publicado). Jornadas XIII de Educación Emocional: educación emocional en la actividad fisica y el deporte. (31 de marzo e 1 de abril). Barcelona.

Bisquerra, R. (2009). Psicopedagogía de las emociones. Madrid: Síntesis.

Boyatzis, R. E. (1998). Transforming Qualitative Information. California: SAGE Publications.

Cea, M A. (1997). Metodología cuantitativa: estrategias y técnicas de investigación social. Madrid: Síntesis. DOI: https://doi.org/10.2307/40183928

Centro de Investigacións Sociolóxicas (CIS) (2016). Percepción de los principais problemas de España. Recuperado de http://www.cis.es/cis/export/sites/default/-Archivos/Indicadores/documentos_html/TresProblemas.html

Châtelet, E. du (1996). Discurso sobre la felicidad. Madrid: Cátedra. 
De la Caba, M.A. (2000). Educación sociopersonal. Bilbao: editorial de la Euskal Herriko Unibersitatea/Universidad de País Vasco.

Delors, J. (1996). La educación encierra un tesoro. Informe á UNESCO da Comisión Internacional sobre a Educación para o século XXI. Madrid: Santillana-Unesco.

Ellis, A. e MacLaren, C. (2004). Las relaciones con los demás. Terapia del Comportamiento Emotivo Racional. Barcelona: Océano.

Lladó Moreno, R. (2012). El coaching educativo y la igualdad de trato. En M. J. Méndez Lois y C. Taboada Lorenzo (Coords.), Igualdade de trato: retos e respostas socioeducativas, (pp. 3945). Santiago de Compostela: Servizo de Publicacións e Intercambio Científico.

Mora, F. (2012). ¿Qué son las emociones? En R. Bisquerra Bisquerra (Coord.), ¿Cómo educar las emociones? La inteligencia emocional en la infancia y la adolescencia. Espluges de Llobregat (Barcelona): Hospital Sant Joan de Déu. Recuperado de: http://faros.hsjdbcn.org/sites/ default/files/faros 6 cast.pdf

Núñez Cubero, L. y Romero López, C. (2009). Emociones, cultura y educación. Un enfoque interdisciplinar. Sevilla: Universidad de Sevilla, Secretariado de Publicaciones.

Pérez Escoda, N. (2016). Cuestionarios del GROP para la evaluación de la competencia emocional (CDE). En J. L. Soler, O., Aparicio, E. Díaz, E. Escolano e A. Rodríguez (Coords.), Inteligencia emocional y bienestar II. Reflexiones, experiencias profesionales e investigaciones investigaciones (pp. 690-705). Zaragoza: Ediciones Universidad San Jorge. Recuperado de http://www.ub.edu/grop/wp-content/uploads/2014/03/CUESTIONARIOS-_grop-ZARAGOZA-2015-2.pdf

Permuy, A. (2013). Proyecto "EmocionadXs", coeducación das emocións en ESO. Santiago: ICEUSC/EXDEHU (non publicado).

Permuy, A. e Méndez, M. J. (2016). La educación emocional del cerebro patriarcal. En Actas das XII Jornadas de Educación Emocional. Educación emocional y neurociencia, celebradas en Barcelona o 11 e 12 de maio de 2016. 124-135.

Sartre, J. P. (2009). El existencialismo es humanismo. Barcelona: Edhasa.

Valdemoros, M. A.; Goicoechea, M. A. (Coords.) (2012). Educación para la convivencia. Propuestas didácticas para la promoción de valores. Madrid: Biblioteca Nueva. DOI: https://doi. org/10.18172/con.665 